\title{
LIPÍDIOS ESTRUTURADOS OBTIDOS A PARTIR DA MISTURA DE GORDURA DE FRANGO, SUA ESTEARINA E TRIACILGLICERÓIS DE CADEIA MÉDIA. I- COMPOSIÇÃO EM ÁCIDOS GRAXOS E EM TRIACILGLICERÓIS
}

\author{
Ming Chih Chiu e Luiz Antonio Gioielli* \\ Departamento de Tecnologia Bioquímico-Farmacêutica, Faculdade de Ciências Farmacêuticas, Universidade de São Paulo, \\ Av. Prof. Lineu Prestes, 580, 05508-900 São Paulo - SP, Brasil \\ Renato Grimaldi \\ Departamento de Tecnologia de Alimentos, Faculdade de Engenharia de Alimentos, Universidade Estadual de Campinas, \\ CP 6091, 13081-970 Campinas - SP, Brasil
}

Recebido em 5/12/06; aceito em 17/8/07; publicado na web em 19/12/07

\begin{abstract}
STRUCTURED LIPIDS FROM CHICKEN FAT, ITS STEARIN AND MEDIUM CHAIN TRIACYLGLYCEROL BLENDS. IFATTY ACID AND TRIACYLGLYCEROL COMPOSITIONS. The purpose of this study is to analyze the interactions that occur in binary and ternary fat blends between medium and long chain triacylglycerols and their structured lipids obtained by chemical interesterification through the analysis of their physico-chemical properties. The synthesized structured triacylglycerols presented from 14.8 to $58.4 \%$ medium chain fatty acids, from 15.7 to $37.2 \%$ saturated fatty acids, from 19.2 to $47.5 \%$ monounsaturated fatty acids, and from 6.7 to $15.2 \%$ essential fatty acids. Chemical interesterification modified the behavior of binary and ternary mixtures and new types of triacylglycerol groups were formed.
\end{abstract}

Keywords: structured lipids; chemical interesterification; triacylglycerol composition.

\section{INTRODUÇÃO}

A utilização de lipídios em nutrição clínica é de grande importância, visto que a gordura é a maior reserva energética corporal e cada grama oxidada fornece cerca de 9,0 kcal, tendo, portanto, alta densidade calórica. Dos lipídios disponíveis como fonte calórica, os triacilgliceróis (TAG) são o maior exemplo e se diferenciam de acordo com o tamanho de suas cadeias carbônicas ${ }^{1}$. Os ácidos graxos de cadeia longa (AGCL) são os mais encontrados na alimentação normal, enquanto que os de cadeia média (AGCM), apesar de suas vantagens clínicas, compõem cerca de $3 \%$ da constituição lipídica de uma refeição ${ }^{2}$.

Desde 2004 o Brasil assumiu a posição de maior exportador mundial de frango. O setor exportador de frangos consolidou-se como o segundo maior no ranking da exportação do agronegócio brasileiro. As condições de clima e meioambiente no Brasil são ideais para a criação de frangos e a matéria-prima necessária à produção de aves é produzida em solo brasileiro (milho e soja) ${ }^{3}$. O Brasil produziu 9,2 milhões de t de carne de frango em 2005. Desse total, 6,5 milhões de $\mathrm{t}$ foram destinadas ao abastecimento interno. O consumo per capita anual foi de $35,5 \mathrm{~kg}$. As exportações em 2005 atingiram 2,8 milhões de $\mathrm{t}$ de carne in natura (frangos inteiros e cortes), além de 84 mil t de produtos processados de frango, atingindo uma receita cambial de US\$ 3,5 bilhões. Atualmente, 142 países consomem a carne de frango produzida no Brasil ${ }^{3,4}$.

Segundo Chiu e Gioielli5, ${ }^{5,6}$ a gordura de frango apresenta-se líquida ou semi-líquida à temperatura ambiente, podendo ser utilizada para diversos fins alimentícios, tais como condimentos, bolos e frituras. Além disso, também pode ser utilizada para melhorar a consistência de cremes cosméticos.

De acordo com Arnaud et al. $^{7}$ existe um mercado crescente para $100 \%$ dos produtos avícolas, especialmente porque estes pro-

*e-mail: lagio@usp.br dutos não são proibidos por nenhuma religião. A gordura de frango pode ser incorporada em produtos de delicatessen como carnes e apresenta substancial valor nutritivo.

De acordo com Lee e Foglia ${ }^{8}$ a gordura de frango contém cerca de $60 \%$ de ácidos graxos insaturados, sendo, portanto, altamente insaturada quando comparada ao sebo bovino. Entre os ácidos graxos insaturados, os monoinsaturados (AGMI), tais como o ácido oléico, são considerados desejáveis no que tange à redução do risco de enfermidades cardiovasculares, pois reduzem os níveis de colesterol sanguíneo em indivíduos não-hipertrigliceridêmicos. Devido à importância desses ácidos graxos na dieta, tem sido recomendado que sua ingestão seja correspondente à metade do total de calorias obtidas a partir das gorduras totais. A gordura de frango é considerada uma fonte de AGMI, uma vez que apresenta teores em torno de 45 a $50 \%$, enquanto que o sebo bovino apresenta somente 30 a $40 \%$ desses ácidos graxos.

Os triacilgliceróis de cadeia média (TCM) são formados por ésteres de glicerol contendo ácidos graxos com 6 a 12 átomos de carbono ${ }^{9,10}$. Os AGCM são absorvidos através da parede intestinal sem ressíntese dos triacilgliceróis nas células intestinais. Os TCM sofrem, predominantemente, $\beta$-oxidação e não são estocados nas células adiposas. Conseqüentemente, constituem boa fonte de energia para pacientes com insuficiência pancreática e má absorção lipídica ${ }^{11,12}$.

A interesterificação química oferece uma importante alternativa para modificar o comportamento de óleos e gorduras sem alterar os ácidos graxos do material de partida. As alterações nas propriedades físico-químicas das gorduras interesterificadas e dos lipídios estruturados são ocasionadas pelas mudanças relativas dos triacilgliceróis componentes, após o rearranjo dos ácidos graxos ${ }^{13,14}$.

Lipídios estruturados específicos, tais como os obtidos através de misturas físicas de óleos vegetais convencionais e posterior interesterificação, têm sido utilizados em estudos de absorção e empregados em nutrição clínica, justamente devido às propriedades desejáveis de seus ácidos graxos e triacilgliceróis sobre a saúde ${ }^{15-17}$. 
Um importante parâmetro na avaliação do produto interesterificado é a composição triacilglicerídica, determinante na caracterização de mudanças físicas e na forma cristalina do produto formulado. A técnica de cromatografia líquida de alta eficiência é uma ferramenta de fácil manuseio, na qual a dificuldade fica por conta da identificação dos picos, uma vez que a separação é feita pelos compostos individuais. As outras técnicas cromatográficas que podem ser utilizadas na quantificação dos triacilgliceróis presentes são a cromatografia gasosa com coluna curta empacotada e a cromatografia gasosa de alta resolução a altas temperaturas com colunas apolares. Nesses dois casos, a identificação dos triacilgliceróis é limitada, pois é baseada no número de átomos de carbono presentes ${ }^{13}$.

O objetivo deste trabalho foi sintetizar lipídios estruturados a partir da gordura de frango, sua estearina e triacilgliceróis de cadeia média através da reação de interesterificação química, e caracterizálos pela análise da composição em ácidos graxos e em triacilgliceróis.

\section{PARTE EXPERIMENTAL}

\section{Material}

A gordura de frango foi obtida após fusão da gordura abdominal à temperatura de $90-100{ }^{\circ} \mathrm{C}$, eliminando-se colágenos através da filtração e a fração aquosa através do processo de separação de fases à temperatura de $70^{\circ} \mathrm{C}$. A seguir, $2 \mathrm{~kg}$ da amostra de gordura foram colocados em recipientes de vidro e armazenados à temperatura de $-20{ }^{\circ} \mathrm{C}$.

A estearina de frango utilizada foi obtida no processo descrito abaixo. Os triacilgliceróis de cadeia média da marca Trigliceril ${ }^{\circledR}$ (mistura de triacilgliceróis compostos principalmente pelos ácidos graxos caprílico e cáprico) foram adquiridos no comércio. Para a reação de interesterificação química foi utilizado metóxido de sódio (Merck) como catalisador.

\section{Processo de obtenção da estearina de frango através do fracionamento a seco da gordura de frango em escala piloto}

O fracionamento foi realizado dentro de um tanque encamisado provido de agitação mecânica. Os parâmetros para o processo foram: fusão da gordura a $70{ }^{\circ} \mathrm{C}$ e sua permanência a esta temperatura durante $15 \mathrm{~min}$, para garantir a completa fusão de qualquer núcleo cristalino. A amostra foi resfriada a uma taxa de $3{ }^{\circ} \mathrm{C} / \mathrm{h}$ até atingir a temperatura de $20^{\circ} \mathrm{C}$. O tempo de permanência neste processo foi de $16 \mathrm{~h}$ até atingir $20^{\circ} \mathrm{C}$ e a amostra permaneceu $8 \mathrm{~h}$ nesta temperatura. Nesta fase ocorreu a formação dos núcleos cristalinos e a permanência da gordura a $20{ }^{\circ} \mathrm{C}$ proporcionou o crescimento dos cristais. A agitação foi realizada com agitador/raspador pneumático à velocidade de 10 a 20 rpm. Finalmente, numa terceira etapa, após concluído o processo de fracionamento, a oleína foi separada da estearina por filtração sob pressão reduzida. Em seguida, a oleína e a estearina foram pesadas para avaliação do rendimento ${ }^{18}$.

\section{Mistura}

As misturas foram preparadas nas proporções mencionadas na Tabela 1 após fusão completa dos cristais à $60-70{ }^{\circ} \mathrm{C}$, sendo posteriormente armazenadas sob resfriamento. Para estudar as interações que ocorrem em misturas binárias e ternárias de gorduras foi utilizado um planejamento experimental centróide simplex de sete experimentos (amostras 1 a 7) e outros três experimentos adicionais (amostras 8 a 10) para validação do modelo ${ }^{19-21}$. A gordura abdominal de frango, sua estearina e os triacilgliceróis de cadeia média foram representados por $\mathrm{x}_{1}, \mathrm{x}_{2}$ e $\mathrm{x}_{3}$, respectivamente. Dessa forma, tem-se que $x_{1}+x_{2}+x_{3}=1$ ou $100 \%$. As três primeiras amostras representam os componentes isoladamente, as outras três amostras são misturas binárias e as quatro amostras restantes são constituídas por misturas ternárias.

Tabela 1. Planejamento experimental centróide simplex de misturas

\begin{tabular}{lccc}
\hline Amostra $\left(\mathrm{n}^{\circ}\right)$ & \multicolumn{3}{c}{ Componentes (proporção m/m) } \\
& $\mathrm{x}_{1}$ & $\mathrm{x}_{2}$ & $\mathrm{x}_{3}$ \\
\hline 1 & 1 & 0 & 0 \\
2 & 0 & 1 & 0 \\
3 & 0 & 0 & 1 \\
4 & $1 / 2$ & $1 / 2$ & 0 \\
5 & $1 / 2$ & 0 & $1 / 2$ \\
6 & 0 & $1 / 2$ & $1 / 2$ \\
7 & $1 / 3$ & $1 / 3$ & $1 / 3$ \\
8 & $2 / 3$ & $1 / 6$ & $1 / 6$ \\
9 & $1 / 6$ & $2 / 3$ & $1 / 6$ \\
10 & $1 / 6$ & $1 / 6$ & $2 / 3$ \\
\hline
\end{tabular}

$\mathrm{x}_{1}=$ gordura abdominal de frango $(\mathrm{GF}) ; \mathrm{x}_{2}=$ estearina de gordura de frango $(\mathrm{EGF}) ; \mathrm{x}_{3}=$ triacilgliceróis de cadeia média $(\mathrm{TCM})$

\section{Interesterificação química}

As amostras (320 g) foram previamente fundidas em forno de microondas até a completa fusão dos cristais $\left(60-70{ }^{\circ} \mathrm{C}\right) \mathrm{e}$ homogeneizadas. Posteriormente, foi adicionado $0,4 \%$ de catalisador (metóxido de sódio). A reação de interesterificação química foi efetuada sob pressão reduzida (56 mm de $\mathrm{Hg}$ ), à temperatura entre 95 a $100{ }^{\circ} \mathrm{C}$ durante $20 \mathrm{~min}$, sob agitação constan$\mathrm{te}^{13,22}$. Ao final da reação, foram adicionados $3 \mathrm{~mL}$ de água destilada com o propósito de inativar o catalisador. Após adição de kieselgur (terra diatomácea) e sulfato de sódio anidro, as amostras foram filtradas a quente com papel de filtro, com a finalidade de remover umidade, sabões e compostos escuros formados. Não foi realizado o refino das amostras após a reação de inter-esterificação química, ou seja, os produtos obtidos foram analisados sob a forma bruta.

\section{Preparação de ésteres metílicos de ácidos graxos}

Visando a análise por cromatografia em fase gasosa, os ácidos graxos das amostras foram transformados em ésteres metílicos, segundo os procedimentos de Hartman e Lago ${ }^{23}$.

\section{Composição em ácidos graxos}

A composição em ácidos graxos das gorduras foi determinada por cromatografia em fase gasosa, segundo normas da $\mathrm{AOCS}^{24}$, método Ce 1-62. Foi empregado cromatógrafo a gás Varian GC, modelo $3400 \mathrm{CX}$, equipado com detector de ionização de chama e Workstation Star Chromatography. Foi utilizada coluna capilar de sílica fundida CP WAX 52 CB (Chrompack), com 30 m de comprimento e $0,25 \mu \mathrm{m}$ de diâmetro interno, contendo $0,25 \mu \mathrm{m}$ de polietilenoglicol. As condições de análise foram: razão de divisão da amostra no injetor $50: 1$; temperatura da coluna: $150{ }^{\circ} \mathrm{C}$ por 5 min, programada até $215{ }^{\circ} \mathrm{C}$ em uma razão de $3{ }^{\circ} \mathrm{C} / \mathrm{min}$; gás de arraste: hélio, em uma vazão de $1,5 \mathrm{~mL}$ por min; gás make-up: hélio a $30 \mathrm{~mL}$ por min; temperatura do injetor: $250{ }^{\circ} \mathrm{C}$; temperatura do detector: $280^{\circ} \mathrm{C}$. A composição qualitativa foi determinada por comparação dos tempos de retenção dos picos com os dos res- 
pectivos padrões de ácidos graxos (Sigma 189-1, 189-3, 189-6, 18919 e Supelco 1895-1, 1-8915-1). A composição quantitativa foi realizada por normalização de área, sendo expressa como porcentagem em massa ${ }^{25}$.

\section{Índice de iodo}

O índice de iodo das amostras foi calculado a partir da composição em ácidos graxos segundos as normas da $\mathrm{AOCS}^{24}$, método Cd $1 \mathrm{c}-85$.

\section{Índice de saponificação}

O índice de saponificação das amostras foi calculado a partir da composição em ácidos graxos segundo as normas da $\mathrm{AOCS}^{24}$, método Cd 3a-94.

\section{Composição em triacilgliceróis}

A análise da composição em triacilgliceróis foi realizada em cromatógrafo gasoso capilar CGC Agilent 6850 Series GC System. Foi utilizada coluna capilar DB-17HT Agilent (50\%-Phenylmethylpolysiloxane), com $15 \mathrm{~m}$ de comprimento x $0,25 \mathrm{~mm}$ de diâmetro interno e contendo $0,15 \mu \mathrm{m}$ de filme. As condições foram: injeção split, razão de 1:30; temperatura da coluna: $250{ }^{\circ} \mathrm{C}$, programada até $350{ }^{\circ} \mathrm{C}$ em uma razão de $5{ }^{\circ} \mathrm{C}$ por min; gás de arraste: hélio, em uma vazão de $1,0 \mathrm{~mL}$ por min; temperatura do injetor: $360{ }^{\circ} \mathrm{C}$; temperatura do detector: $375{ }^{\circ} \mathrm{C}$; volume injetado: $1,0 \mu \mathrm{L}$.

A identificação dos grupos de triacilgliceróis foi realizada através da comparação dos tempos de retenção, segundo os procedimentos de Grimaldi ${ }^{22}$ e Antoniossi Filho ${ }^{26}$.

\section{RESULTADOS E DISCUSSÃO}

A Tabela 2 apresenta os rendimentos das frações estearina e oleína obtidas a partir da gordura de frango, por meio do fracionamento a seco com programação de temperatura de resfriamento. Os resultados obtidos para o rendimento da fração estearina foram cerca de duas vezes superiores aos encontrados por Chiu et al. ${ }^{27}$ para a mesma gordura $\left(9,6 \%\right.$ de rendimento para a estearina a $\left.20{ }^{\circ} \mathrm{C}\right)$. Dessa forma, observou-se que o método de fracionamento com programação de temperatura e agitação mostrou-se mais eficaz que o fracionamento isotérmico e estático. Arnaud et al. ${ }^{7}$ pesquisaram o método de fracionamento a seco da gordura de frango com programação de temperatura, com temperatura final de $13,5^{\circ} \mathrm{C}$. Estes autores obtiveram rendimentos de $18 \%$ para a estearina e $82 \%$ para a oleína.

Tabela 2. Rendimentos das frações estearina e oleína obtidas pelo fracionamento da gordura de frango a $20^{\circ} \mathrm{C}$

\begin{tabular}{lc}
\hline Amostras & Rendimento $(\%)^{*}$ \\
\hline Estearina & 16,5 \\
Oleína & 83,5 \\
\hline
\end{tabular}

*Valores médios de processamento

A Tabela 3 apresenta a composição em ácidos graxos e os índices de iodo e saponificação da gordura de frango (amostra 1), de sua estearina (amostra 2), dos triacilgliceróis de cadeia média (amostra 3) e das respectivas misturas binárias (amostras 4, 5 e 6) e ternárias (amostras 7, 8, 9 e 10).

Estes resultados exprimem a média de duas determinações. De modo geral, os resultados das amostras 1 a 3 estão de acordo com os limites encontrados na literatura e dentro das especificações comerciais dos fabricantes ${ }^{5-8,19,27-30}$.

Para a gordura de frango, as pequenas diferenças existentes provavelmente são devidas a fatores intrínsecos às aves, tais como idade, sexo, raça, clima, tipo de alimentação e de tecido adiposo analisado ${ }^{6,27,31,32}$.

Os resultados mostraram que a gordura de frango apresenta em sua composição principalmente os ácidos oléico $(43,4 \%)$, palmítico $(24,7 \%)$ e linoléico $(17,2 \%)$. Esta gordura é semi-líquida à temperatura ambiente devido ao alto teor de ácidos graxos insaturados como o oléico e o linoléico. Para a estearina da gordura de frango, os teores dos ácidos oléico e palmítico estiveram relativamente próximos, sendo respectivamente de 38,6 e $34,2 \%$. Por apresentar altas concentrações de ácidos graxos saturados, como palmítico $(34,2 \%)$ e esteárico $(9,1 \%)$, a estearina é sólida à temperatura ambiente. Esta fração apresentou menor índice de iodo em relação à gordura de frango, devido ao seu maior teor de ácidos graxos saturados. Os índices de saponificação obtidos para a gordura de frango e sua estearina foram próximos (196,4 e 197,9, respectivamente), uma vez que a massa molar média dos ácidos graxos nestas duas gorduras é praticamente a mesma ${ }^{5,6}$.

Os resultados das amostras de 4 a 6 (misturas binárias de gordura de frango e estearina, gordura de frango e TCM e estearina e TCM, respectivamente) apresentaram faixas de ácidos graxos de cadeias médias de 27,5 a 45,2\%, de ácidos graxos saturados de 17,5 a 36,9\%, de ácidos graxos monoinsaturados de 25,0 a 46,7\% e de ácidos graxos polinsaturados de 8,1 a $16,4 \%$. Os índices de iodo e saponificação variaram de 36,3 a 69,9, e de 197,1 a 242,9, respectivamente.

As amostras ternárias de 7 a 10 (misturas ternárias de gordura de frango, estearina e TCM nas proporções $1 / 3,1 / 3,1 / 3 ; 2 / 3,1 / 6$, $1 / 6 ; 1 / 6,2 / 3,1 / 6 ; 1 / 6,1 / 6,2 / 3$, respectivamente) apresentaram variações em faixas compreendidas de 13,1 a 64,7, 13,2 a 34,0, 16,4 a 42,4 e 5,7 a 15,1\% para os ácidos graxos de cadeia média, saturados, monoinsaturados e polinsaturados, respectivamente. Os índices de iodo e saponificação variaram de 24,4 a 63,8 e 208,1 a 271,7 , respectivamente.

A Tabela 4 apresenta a composição em ácidos graxos e os índices de iodo e saponificação da gordura de frango, sua estearina, triacilgliceróis de cadeia média interesterificados e dos lipídios estruturados. Estes resultados exprimem a média de duas determinações. Foram obtidos lipídios estruturados contendo de 14,8 a 58,4\% de ácidos graxos de cadeia média, de 15,7 a 37,2\% de ácidos graxos saturados, de 19,2 a 47,5\% de ácidos graxos monoinsaturados e de 6,7 a 15,2\% de ácidos graxos essenciais (linoléico e $\alpha$-linolênico), que apresentaram composição equilibrada entre os ácidos graxos presentes. Estes lipídios estruturados apresentaram características plásticas adequadas para aplicação em produtos alimentícios.

Lee e Foglia ${ }^{29}$ sintetizaram, purificaram e caracterizaram lipídios estruturados produzidos a partir de gordura de frango através de acidólise enzimática e da incorporação de ácido caprílico aos triacilgliceróis da gordura de frango. Estes autores concluíram que houve incorporação de $62 \%$ de ácido caprílico aos triacilgliceróis da gordura de frango, tendo este ácido graxo preferência pelas posições $s n-1,3$.

De modo geral, não houve mudanças significativas na composição em ácidos graxos das amostras 1 a 10 após a interesterificação, confirmando o princípio de que este método de modificação altera apenas a posição dos ácidos graxos nas moléculas dos triacilgliceróis ${ }^{15,33}$. Contudo, as misturas binárias e ternárias (amostras de 5 a 10) que possuíam TCM em sua composição apresentaram redução nos ácidos graxos de cadeia média após a reação. Isso pode ser explicado pelas condições de reação, uma vez que a interesterificação química foi realizada à temperatura ele- 
Tabela 3. Composição em ácidos graxos e índices de iodo e saponificação das amostras individuais e das misturas binárias e ternárias antes da interesterificação química

\begin{tabular}{|c|c|c|c|c|c|c|c|c|c|c|}
\hline \multirow[t]{2}{*}{ Ácidos Graxos (\%) } & \multicolumn{9}{|c|}{ Amostras antes da reação de interesterificação* } & \multirow[b]{2}{*}{10} \\
\hline & 1 & 2 & 3 & 4 & 5 & 6 & 7 & 8 & 9 & \\
\hline C6:0 capróico & - & - & 0,7 & - & 0,4 & 0,4 & 0,4 & - & - & 1,1 \\
\hline C8:0 caprílico & - & - & 65,3 & - & 30,0 & 28,8 & 17,7 & 8,6 & 9,4 & 44,7 \\
\hline C10:0 cáprico & - & - & 33,2 & - & 14,8 & 13,6 & 9,5 & 4,5 & 4,7 & 18,9 \\
\hline C12:0 láurico & - & - & 0,8 & - & 0,4 & - & - & - & - & 0,4 \\
\hline C14:0 mirístico & 0,6 & 0,8 & - & 0,7 & 0,5 & 0,5 & 0,5 & 0,6 & 0,6 & 0,3 \\
\hline C16:0 palmítico & 24,7 & 34,2 & - & 28,9 & 13,5 & 18,6 & 21,4 & 23,1 & 26,5 & 10,0 \\
\hline C16:1 palmitoléico & 7,1 & 6,3 & - & 6,7 & 4,2 & 3,5 & 5,1 & 6,2 & 5,6 & 2,5 \\
\hline C18:0 esteárico & 6,0 & 9,1 & - & 7,3 & 3,2 & 5,0 & 5,4 & 5,7 & 6,9 & 2,5 \\
\hline C18:1 oléico & 43,4 & 38,6 & - & 40,0 & 23,2 & 21,5 & 29,6 & 36,2 & 33,0 & 13,9 \\
\hline C18:2 linoléico & 17,2 & 10,8 & - & 15,5 & 9,3 & 7,7 & 9,9 & 14,3 & 12,5 & 5,4 \\
\hline C18:3 linolênico & 1,0 & 0,2 & - & 0,9 & 0,5 & 0,4 & 0,5 & 0,8 & 0,8 & 0,3 \\
\hline$\overline{\text { I.I* }}$ & 76 & 59 & - & 70 & 42 & 36 & 49 & 64 & 57 & 24 \\
\hline I.S* & 196 & 198 & 338 & 197 & 243 & 241 & 223 & 208 & 210 & 272 \\
\hline$\Sigma$ Cadeias médias & - & - & 99,2 & - & 45,2 & 42,8 & 27,6 & 13,1 & 14,1 & 64,7 \\
\hline$\Sigma$ Saturados & 31,3 & 44,1 & 0,8 & 36,9 & 17,6 & 24,1 & 27,3 & 29,4 & 34,0 & 13,2 \\
\hline$\Sigma$ Monoinsaturados & 50,5 & 44,9 & - & 46,7 & 27,4 & 25,0 & 34,7 & 42,4 & 38,6 & 16,4 \\
\hline$\Sigma$ Poliinsaturados & 18,2 & 11,0 & - & 16,4 & 9,8 & 8,1 & 10,4 & 15,1 & 13,3 & 5,7 \\
\hline
\end{tabular}

I.I*= Índice de iodo (g iodo/100 g); I.S*= Índice de saponificação (mg KOH/g); *Média de duas determinações

Tabela 4. Composição em ácidos graxos e índices de iodo e saponificação das amostras individuais interesterificadas e dos lipídios estruturados

\begin{tabular}{|c|c|c|c|c|c|c|c|c|c|c|}
\hline \multirow[t]{2}{*}{ Ácidos Graxos (\%) } & \multicolumn{9}{|c|}{ Amostras após a reação de interesterificação* } & \multirow[b]{2}{*}{10} \\
\hline & 1 & 2 & 3 & 4 & 5 & 6 & 7 & 8 & 9 & \\
\hline C6:0 capróico & - & - & 1,6 & - & 0,2 & 0,3 & - & - & - & 0,6 \\
\hline C8:0 caprílico & - & - & 67,2 & - & 25,5 & 24,0 & 9,9 & 10,8 & 9,9 & 36,5 \\
\hline C10:0 cáprico & - & - & 30,5 & - & 13,6 & 14,4 & 8,3 & 4,9 & 4,9 & 21,3 \\
\hline C12:0 láurico & - & - & 0,7 & - & 0,4 & 0,4 & 0,1 & - & - & 0,5 \\
\hline C14:0 mirístico & 0,7 & 0,8 & - & 0,8 & 0,4 & 0,5 & 0,6 & 0,6 & 0,6 & 0,3 \\
\hline C16:0 palmítico & 24,8 & 34,9 & - & 29,1 & 15,1 & 19,9 & 23,5 & 22,3 & 26,0 & 11,9 \\
\hline C16:1 palmitoléico & 7,2 & 6,7 & - & 6,7 & 4,6 & 4,0 & 5,4 & 5,9 & 5,5 & 2,8 \\
\hline C18:0 esteárico & 6,0 & 9,3 & - & 7,4 & 3,6 & 5,2 & 5,9 & 5,5 & 6,8 & 3,0 \\
\hline C18:1 oléico & 43,2 & 38,9 & - & 40,8 & 25,8 & 22,4 & 32,8 & 35,3 & 33,0 & 16,4 \\
\hline C18:2 linoléico & 17,2 & 9,1 & - & 14,5 & 10,2 & 8,4 & 12,8 & 13,9 & 12,6 & 6,4 \\
\hline C18:3 linolênico & 0,9 & 0,3 & - & 0,7 & 0,6 & 0,5 & 0,7 & 0,8 & 0,7 & 0,3 \\
\hline I.I* & 76 & 56 & - & 69 & 46 & 39 & 57 & 62 & 57 & 29 \\
\hline I.S* & 196 & 198 & 340 & 197 & 235 & 236 & 213 & 211 & 210 & 260 \\
\hline$\Sigma$ Cadeias médias & - & - & 99,3 & - & 39,3 & 38,7 & 18,2 & 15,7 & 14,8 & 58,4 \\
\hline$\Sigma$ Saturados & 31,5 & 45,0 & 0,7 & 37,3 & 19,5 & 26,0 & 30,1 & 28,4 & 33,4 & 15,7 \\
\hline$\Sigma$ Monoinsaturados & 50,4 & 45,6 & - & 47,5 & 30,4 & 26,4 & 38,2 & 41,2 & 38,5 & 19,2 \\
\hline$\Sigma$ Polinsaturados & 18,1 & 9,4 & - & 15,2 & 10,8 & 8,9 & 13,5 & 14,7 & 13,3 & 6,7 \\
\hline
\end{tabular}

I.I*= Índice de iodo (g iodo/100 g); I.S*= Índice de saponificação (mg KOH/g); *Média de duas determinações

vada $\left(95^{\circ} \mathrm{C}\right)$ e sob pressão reduzida, provavelmente tendo havido volatilização de triacilgliceróis que continham estes ácidos graxos. Como consequiência da perda dos triacilgliceróis de cadeia média houve acréscimo da proporção dos demais ácidos graxos que compõem as misturas.

Não houve mudanças nos índices de iodo e saponificação dos componentes individuais (amostras de 1 a 3) e da mistura binária (amostra 4) após a reação. Estes resultados estiveram de acordo com os obtidos por D'Agostini e Gioielli3 ${ }^{33}$. A mudança no índice de saponificação para as misturas binárias e ternárias (amostras de 5 a 10) após a reação pode ser devida às perdas de ácidos graxos saturados de cadeia média, causando aumento da proporção dos demais ácidos graxos que compõem as misturas.
A confirmação da ocorrência da reação de interesterificação é freqüentemente realizada pelo monitoramento da cor, ponto de fusão e perfil de sólidos. Segundo vários autores, o desenvolvimento da cor marrom é insuficiente para confirmar o rearranjo completo dos ácidos graxos nas moléculas de glicerol. Os fatores predominantes para que a reação seja efetiva são a qualidade e o teor do catalisador, a temperatura de reação e a qualidade do óleo ${ }^{22}$.

A Tabela 5 apresenta os principais triacilgliceróis individuais que compõem os diversos grupos classificados segundo o número de carbonos, para as amostras originais. Estes resultados foram obtidos através de cromatografia gasosa à temperatura elevada, com identificação dos picos individuais.

As Figuras 1 a 4 mostram as variações na composição em 
Tabela 5. Composição em triacilgliceróis individuais e quanto ao número de carbonos (NC) da gordura de frango, sua estearina e triacilgliceróis de cadeia média antes da interesterificação química

\begin{tabular}{lcccc}
\hline NC & Triacilgliceróis & \multicolumn{3}{c}{ Amostras } \\
\cline { 3 - 5 } & & $\begin{array}{c}\text { Gordura de } \\
\text { frango }\end{array}$ & Estearina & TCM \\
\hline 22 & CaCiCi & - & - & 4,8 \\
24 & CiCiCi & - & - & 39,9 \\
26 & CiCiC & - & - & 38,7 \\
28 & CiCC & - & - & 14,1 \\
30 & CiCLa-CCC & - & - & 2,5 \\
48 & PPP & 2,3 & 10,9 & - \\
& MPO & 3,0 & 3,6 & - \\
& PPP & 2,0 & 1,5 & - \\
50 & PPS & 2,0 & 8,0 & - \\
& PPO & 13,4 & 17,6 & - \\
& POP & 12,2 & 10,7 & - \\
& LPP & 4,6 & 2,1 & - \\
52 & PSO & 5,1 & 7,2 & - \\
& POO & 19,9 & 17,6 & - \\
& POL & 16,4 & 9,5 & - \\
& POO & 4,9 & 1,7 & - \\
& Outros & - & 1,7 & - \\
54 & SOO & 2,6 & 2,0 & - \\
& OOO & 5,6 & 3,4 & - \\
& LOS & 0,9 & 0,4 & - \\
& LOO-LLO & 5,1 & 2,0 & - \\
& Outros & - & - & - \\
\hline
\end{tabular}

$\mathrm{Ca}=$ Ácido Capróico; $\mathrm{Ci}=$ Ácido Caprílico; $\mathrm{C}=$ Ácido Cáprico; $\mathrm{La}=$ Ácido Láurico; $\mathrm{M}=$ Ácido Mirístico; $\mathrm{P}=$ Ácido Palmítico; $\mathrm{P}_{\mathrm{O}}=$ Ácido Palmitoléico; $\mathrm{S}=$ Ácido Esteárico; $\mathrm{O}=$ Ácido Oléico; $\mathrm{L}=$ Ácido Linoléico.

triacilgliceróis quanto ao número de carbonos das misturas ternárias e seus correpondentes lipídios estruturados.

A composição em triacilgliceróis das misturas e dos lipídios estruturados foi expressa em número de átomos de carbono da cadeia devido à dificuldade de identificação dos tipos de triacilgliceróis formados após a reação de interesterificação. Os lipídios estruturados apresentaram novos tipos de triacilgliceróis contendo 32 a 46 átomos de carbono.

As misturas ternárias (am 7ai, am 8ai, am 9ai e am 10ai) apresentaram dois grupos distintos de triacilgliceróis que continham 22 a 30 átomos de carbono e 48 a 54 átomos de carbono (Figuras 1 a 4). Isso demonstra que o processo de mistura é um método físico

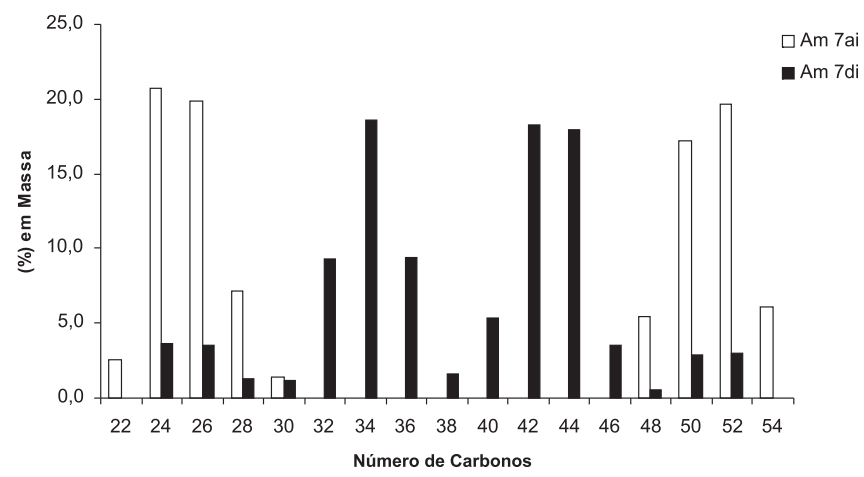

Figura 1. Composição percentual em triacilgliceróis quanto ao número de carbonos da mistura ternária entre gordura de frango (1/3), estearina (1/3) e TCM (1/3) antes (Am 7ai) e após a interesterificação (Am 7di)

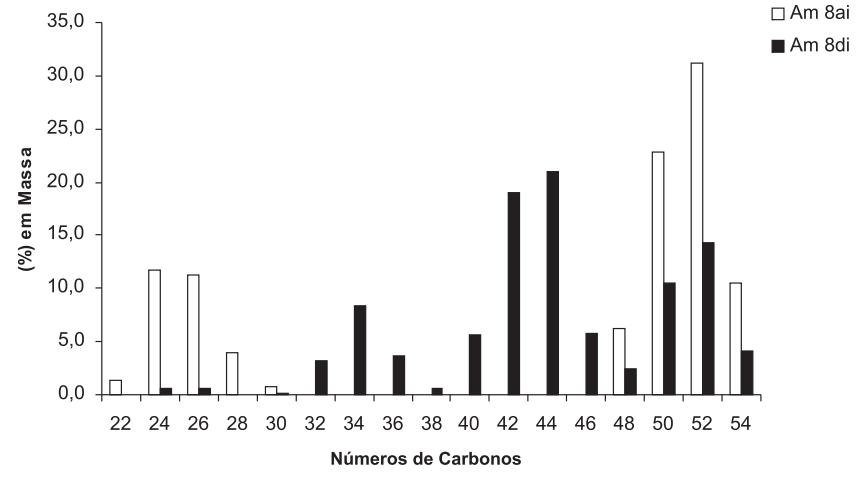

Figura 2. Composição percentual em triacilgliceróis quanto ao número de carbonos da mistura ternária entre gordura de frango (2/3), estearina (1/6) e TCM (1/6) antes (Am 8ai) e após a interesterificação (Am 8di)

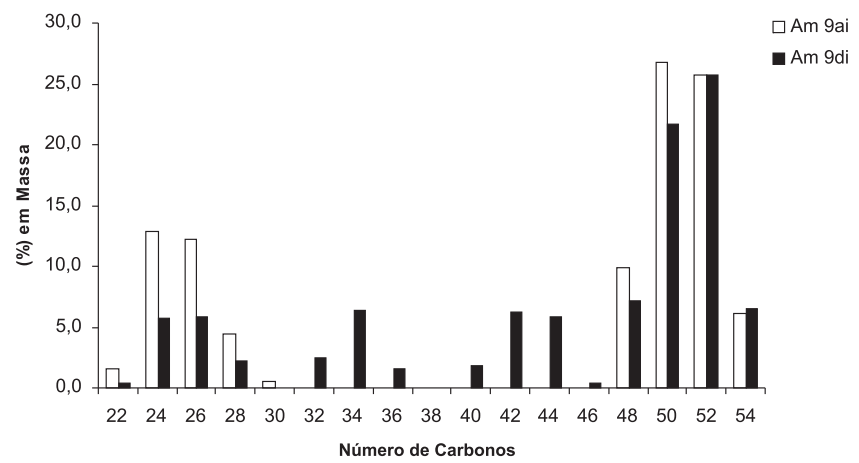

Figura 3. Composição percentual em triacilgliceróis quanto ao número de carbonos da mistura ternária entre gordura de frango (1/6), estearina (2/3) e TCM (1/6) antes (Am 9ai) e após a interesterificação (Am 9di)

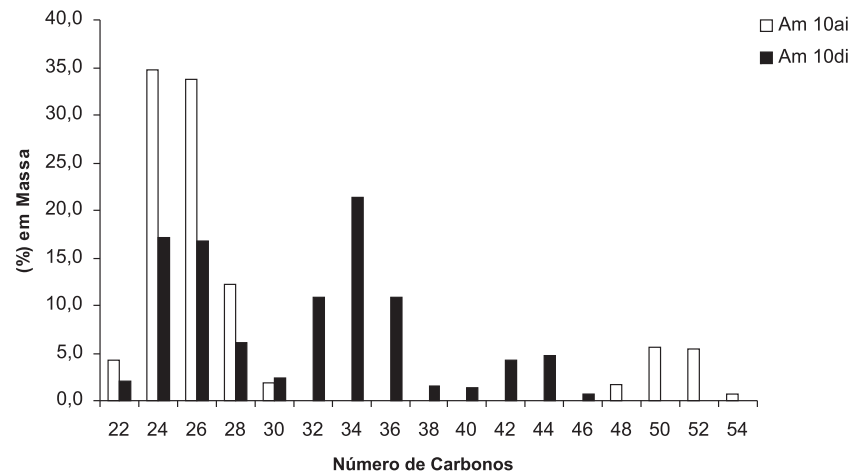

Figura 4. Composição percentual em triacilgliceróis quanto ao número de carbonos da mistura ternária entre gordura de frango (1/6), estearina (1/6) e TCM (2/3) antes (Am 10ai) e após a interesterificação (Am 10di)

de pequena modificação de óleos e gorduras e que não provoca implicações metabólicas de grande impacto quando comparado ao efeito causado pelas gorduras interesterificadas ${ }^{34}$.

Os lipídios estruturados (am 7di, am 8di, am 9di e am 10di) apresentaram triacilgliceróis compreendidos em faixas de moléculas com 22 a 54 átomos de carbono, mostrando a combinação dos ácidos graxos de cadeia média e longa ocorrida na interesterificação. Foram formados novos triacilgliceróis com número intermediário de carbonos (de 32 a 46), inexistentes nas amostras originais (Figuras 1 a 4).

Para os lipídios estruturados, as espécies de triacilgliceróis foram separadas em três grupos distintos com número de átomos de 
carbono nas faixas de 22 a 30, 32 a 46 e 48 a 54. Quando os TCM foram incorporados aos lipídios estruturados houve a formação do grupo com 32 a 46 átomos de carbono, caracterizando um lipídio estruturado composto por ácidos graxos de cadeia média e por um ácido graxo de cadeia longa proveniente da gordura de frango. Este tipo de triacilglicerol pode ser designado como MML ( $\mathrm{M}=$ ácido graxo de cadeia média, $\mathrm{L}=$ ácido graxo de cadeia longa). Os grupos de triacilgliceróis que continham de 22 a 30 átomos de carbono foram formados por TCM e os que apresentaram de 48 a 54 átomos de carbono foram provenientes da gordura de frango.

\section{CONCLUSÃO}

Foram obtidos lipídios estruturados contendo de 14,8 a $58,4 \%$ de ácidos graxos de cadeia média, de 15,7 a 37,2\% de ácidos graxos saturados, de 19,2 a 47,5\% de ácidos graxos monoinsaturados e de 6,7 a 15,2\% de ácidos graxos essenciais, que tiveram composição equilibrada entre os ácidos graxos presentes.

Antes da reação de interesterificação houve dois grupos distintos de triacilgliceróis (de 22 a 30 e de 48 a 54 átomos de carbono). Após a reação, houve surgimento de novos grupos de triacilgliceróis (de 32 a 46 átomos de carbono), inexistentes nas amostras originais.

\section{MATERIAL SUPLEMEMENTAR}

No material suplementar, disponível gratuitamente em http:// quimicanova.sbq.org.br na forma de arquivo PDF, estão contidas as Figuras referentes às composições percentuais em triacilgliceróis das amostras individuais e das misturas binárias da gordura de frango, sua estearina e triacilgliceróis de cadeia média, antes e após a interesterificação (Figuras 1S a 6S).

\section{AGRADECIMENTOS}

À Fundação de Amparo à Pesquisa do Estado de São Paulo FAPESP, à Coordenação de Aperfeiçoamento de Pessoal de Nível Superior - CAPES e ao Conselho Nacional de Desenvolvimento Científico e Tecnológico - CNPq, pelo auxílio financeiro e pelas bolsas concedidas aos autores.

\section{REFERÊNCIAS}

1. Auerbach, M. H.; Klemann, L. P.; Heydinger, J. A. Em Structured and Modified Lipids; Gunstone, F. D., ed.; Marcel Dekker, Inc.: New York, 2001, p. 485
2. D’Agostini, D.; Tese de Doutorado, Universidade de São Paulo, Brasil, 2001.

3. http://www.abef.com.br, acessada em Outubro 2006.

4. http://www.apa.com.br, acessada em Outubro 2006.

5. Chiu, M. C.; Gioielli, L. A.; Rev. Bras. Ciênc. Farm. 2002a, 38, 95.

6. Chiu, M. C.; Gioielli, L. A.; Ciênc. Tecnol. Aliment. 2002b, 22, 151.

7. Arnaud, E.; Relkin, P.; Pina, M.; Collignan, A.; Eur. J. Sci. Technol. 2004, 106, 591.

8. Lee, K. T.; Foglia, T. A.; J. Food Sci. 2000, 65, 826.

9. Lopez-Hernandez, A.; Garcia, H. S.; Hill Jr. C, G.; J. Food Sci. 2005, 70, 365.

10. Colleone, V. V. Em Entendendo a gordura: os ácidos graxos; Curi, R.; Pompéia, C.; Miyasaka, C. K.; Procópio, J., eds.; Manole: São Paulo, 2002, p. 439.

11. Tsuji, H.; Kasai, M.; Takeuchi, H.; Nakamura, M.; Okazaki, M.; Kondo, K.; J. Nutr. 2001, 131, 2853.

12. Jennings, B. H.; Akoh, C. C.; Food Chem. 2001, 72, 273.

13. Grimaldi, R.; Gonçalves, L. A. G.; Ando, M. Y.; Quim. Nova 2005, 28, 633.

14. Castro, H. F.; Mendes, A. A.; Santos, J. C.; Quim. Nova 2004, 27, 146.

15. D'Agostini, D.; Ferraz, R. C.; Gioielli, L. A.; Sotero Solis, V. E.; Grasas $y$ Aceites 2001a, 52, 214.

16. D’Agostini, D.; Ferraz, R. C.; Gioielli, L. A.; Sotero Solis, V. E.; Alimentaria 2001b, 38, 47

17. Gioielli, L. A. Em ref. 10, p. 457.

18. Chiu, M. C.; Grimaldi, R.; Gioielli, L. A.; Rev. Bras. Ciênc. Farm. 2007, $43,421$.

19. D'Agostini, D.; Ferraz, R. C.; Gioielli, L. A.; Rev. Bras. Ciênc. Farm. 2000, $36,147$.

20. Cornell, J. A.; Experiments with mixtures. Designs, models and the analysis of mixture data, Wiley: New York, 2002.

21. Barros Neto, B.; Scarminio, I. S.; Bruns, R. E.; Como fazer experimentos. Pesquisa e desenvolvimento na ciência e na indústria, Unicamp: Campinas, 2001, p. 401.

22. Grimaldi, R.; Tese de Doutorado, Universidade Estadual de Campinas, Brasil, 1999

23. Hartman L.; Lago, R. C. A.; Lab. Pract. 1973, 22, 475.

24. AOCS; Official methods and recommended practices of the American Oil Chemist's Society, Champaign: Illinois, $5^{\text {th }}$ ed., 1998.

25. Díaz Gamboa, O. W.; Gioielli, L. A.; Quim. Nova 2006, 29, 646.

26. Antoniossi Filho, N. R.; Tese de Doutorado, Universidade de São Paulo, Brasil, 1995.

27. Chiu, M. C.; Gioielli, L. A.; Sotero Solis, V. E.; Grasas y Aceites 2002, 53, 298

28. Marikkar, J. M. N.; Ghazali, H. M.; Long, K.; Lai, O. M.; Food Res. Int. 2003, 36, 1047.

29. Lee K. T.; Foglia T. A.; J. Am. Oil Chem. Soc. 2000, 77, 1027.

30. D'Agostini, D.; Gioielli, L. A.; Ferraz, R. C.; Rev. Port. Farm. 2000, 50, 161.

31. Vizcarrondo, C. A.; De Padilla, F. C.; Martín, E.; Arch. Latin. Amer. Nutr. 1998, 48, 354

32. Stauffer, C. E.; Fats and Oils, Eagan Press: St. Paul, 1996, p. 19.

33. D’Agostini, D.; Gioielli, L. A.; Rev. Bras. Ciênc. Farm. 2002, 38, 345.

34. Dian, N. L. H. M.; Sundram, K.; Idris, N. A.; J. Am. Oil Chem. Soc. 2006, 83,739 . 